\title{
Transmisión identitaria judía a través de la educación judía en Chile
}

Jewish identity transmission trough the Jewish education in Chile

Dra. Deby Roitman debyroitman@gmail.com Centro de Estudios Judaicos

Universidad de Chile

Chile

\section{Resumen}

El artículo trata sobre la educación judía como transmisora de identidad judía y de cómo se fundó en Chile un colegio hebreo con ese propósito específico. Se detalla el concepto de identidad y los identificadores, así como una descripción de las materias Judaicas dentro del Instituto Hebreo y cuáles deben de ser los ejes judaicos centrales de guía para su implementación y transmisión.

Palabras claves: Identidad judía - Educación judía - Colegio judío en Chile

\begin{abstract}
The article deals with the transmission of Jewish identity through Jewish education and how the Hebrew school in Chile was founded for that specific purpose. It details the concept of identity and its features, and how the Judaic subjects are taught and what should be the central Jewish guide shafts for their implementation.
\end{abstract}

Keywords: Jewish identity - Jewish education - Jewish school in Chile 


\section{Identidad judía ¿De qué trata?}

En razón de la plasticidad y la flexibilidad que muestra la identidad hoy en día, cada judío puede elegir cómo pertenecer, al situarse ante un mosaico de nuevas posibilidades de vivir el judaísmo. ${ }^{1}$ Definir la identidad judía con base a un solo criterio se ha vuelto virtualmente imposible (Webber, 1997, pp. 263-265; Eleazar, 1997/98, 122). La diversidad ha tornado al judaísmo en un complejo de categorías que incluye una vasta extensión de las mismas y cada una viene acompañada de su propia enunciación y exposición de la otredad y singularidad judía. Bajo este principio, Arnow (1994, p. 30) absorbiendo definiciones de autores como Herman y Meyer, todos apelando al pluralismo como común denominador, concibe la identidad judía "como la experiencia interna del yo (self) en relación con elementos religiosos, políticos, étnicos y/o culturales del judaísmo, el pueblo judío e Israel".

Partiendo de la definición anterior, en la actualidad, el judaísmo se afirma como un conjunto interactivo de múltiples componentes - religión, historia, pueblo, tradición, moral, ética, hábitos, sentimientos, actitudes, normas y valores -, que se organizan de manera diferente y dispareja; y juntos conforman una miscelánea de diversidad dentro del pueblo judío, cuyas categorías no siempre se hayan reñidas entre sí, sino que más bien se traslapan y son de tipo incluyente. Bajo este concepto, la identidad judía, como cualquier otra identidad, debe de marcar sus diferencias. Está compuesta por una suma de variables, que pueden ser consideradas todas en su conjunto o sólo algunas. El Shabat, la literatura, la liturgia, las festividades judías, la Torá, la historia, el Estado de Israel, la sinagoga, el hebreo, los preceptos, lo culinario, las tradiciones, los rezos, la música, los bailes, la kashrut, la Shoa, el Bar Mitzva, la jupá y muchas más, son parte indiscutible de este conglomerado que denominamos identidad judía.

\footnotetext{
${ }^{1}$ Gran parte de lo escrito se basa en la investigación doctoral "Identidad Colectiva y Consenso Cultural: El Grupo Judío en la Ciudad de México a Principios del Siglo XXI, un Estudio de Caso”, realizada por la autora en la Universidad Nacional Autónoma de México, 2005
} 
Herman (1977, p. 69), estudioso del judaísmo en la Modernidad, definió la identidad judía como una "mezcla peculiar de elementos religiosos y nacionales inexplicables unidos y entre-tejidos entre sí", lo cual implica por un lado un sustrato común paralelamente a su diversidad interna.

Bajo ésta línea se considera que elementos como la religión y la remembranza por Sión, la diáspora y la comunidad, han sido constantes del pueblo judío a pesar de las alteraciones experimentadas a lo largo de la historia. Eventos recientes como el Holocausto (Shoa) y la creación del Estado de Israel han enfatizado y re-articulado la sensación y la pertenencia al judaísmo en la nueva era, empero perdura un vínculo medular con el pasado, una memoria colectiva que atraviesa fronteras espaciales y temporales.

\section{Identificadores judíos}

Los identificadores, es decir, los rasgos y características particulares del pueblo judío, se han ido construyendo y reforzando a lo largo de la historia, inicialmente sobre la base de su dimensión religiosa-comunitaria y, con el tiempo, específicamente en la Modernidad ${ }^{2}$, a través de la diferenciación y pluralización de opciones para articular su identidad.

El espacio religioso, otrora dominante, a partir de la secularización y la individualización, procesos propios de la Modernidad, comparte dimensiones diferenciadas como lo cultural, lo étnico y lo nacional. Esta posición pluralista apuntó a la posibilidad de convivencia de diferentes ejercicios de lo judío y autodefiniciones de lo que es ser judío (Webber, 1992; Elazar, 1999; Eisen, 1998; Birnbaum \& Katzenelson, 1995; Katz, 1998; Baron, 1965), provocando un proceso de flexibilización, diversificación y rearticulación religiosa que

2 La ubicación temporal - la época Moderna - y espacial - Europa - son los escenarios principales del las transformaciones del judaísmo y su identidad. Esta tendencia Eurocéntrica se justifica por el historiador inglés Eric Hobsbawn (1998) en su libro La Era de la Revolución, 1789-1848: "si su perspectiva es principalmente europea... es porque en dicho período el mundo - o al menos gran parte de él - se transformó en una base europea...”. 
permitió la redefinición del lugar de los rituales y las prácticas judías tradicionales (Sacks, 1994).

El ser judío pasa de posición imperativa y totalitaria a condición voluntaria; hoy es el individuo el que decide por sí mismo lo que significa pertenecer a un grupo étnico particular, con quién compartir su afiliación e inclusive elegir cuáles son las obligaciones que esta pertenencia [le] implica. De aquí resulta que dentro del mismo colectivo judío, coexisten distintas modalidades de expresión del judaísmo en los cuales cada individuo decreta (para sí mismo, idiosincráticamente) el valor preciso de cada uno de los identificadores judíos, es decir, cada uno decide con que identificarse.

Los cinco identificadores básicos, que se derivan del análisis de la literatura sobre el tema (Roitman, 2005), son religión, conciencia de pueblo, tradiciones, Israel y Holocausto (Shoa); son producto de un entretejido de rasgos que han acompañado al pueblo judío a lo largo de su historia, aunado a elementos que han sido re-articulados y otros que fueron insertados en épocas recientes.

La idea central es que los identificadores, a raíz del consenso cultural existente dentro del colectivo particular -el grupo judío-, son reconocidos por cada uno de sus integrantes. Este reconocimiento no significa que cada judío se identifique a nivel personal y particular, es decir, que no le asignen un mismo valor a cada uno de los elementos identitarios. El reconocimiento de estas características como parte del ser judío entra dentro del ámbito de lo colectivo, pero el valor y peso asignado a los identificadores es una cuestión de orden individual.

La religión, como testimonio fundacional del judaísmo, está presente como rasgo identificador sine qua non del judaísmo; elemento considerado como una fuente de vinculación grupal e individual con el judaísmo, como una forma de vivir y experimentar la identidad judía, cuyo enlace tiene que ver con lo sagrado y la creencia en un solo Dios. Se manifiesta principalmente en un complejo de creencias, normas y valores particulares, así 
como en la constante realización de prácticas tradicionales (Della Pergola, 1999) e implica una vida gregaria constatando que gran parte de los ritos judaicos se llevan a cabo de forma colectiva, en comunidad.

A raíz de la secularización, gradualmente se generaron dentro del judaísmo denominaciones religiosas cuyas diversificaciones surgen a partir de la selección, resignificación y reinterpretación de la observancia de los preceptos y rituales judíos.

Frente a la creación de esta categorización en el área religiosa, Sacks (1994) argumenta que el judaísmo pasa de ser sustantivo a ser adjetivo; significa que a partir de ésta clasificación a los judíos se les tiene que "nombrar" para ser diferenciados entre ellos mismos. A partir de esta nueva diferenciación aumenta la pluralidad en el ámbito religioso y provoca una heterogeneidad antes desconocida dentro del judaísmo.

La conciencia de pueblo, como sentimiento de pertenencia a una misma unidad colectiva, ha sido una constante en la existencia del pueblo judío y es un factor relevante de cohesión que abarca y comprende a la mayor parte del colectivo y pone el énfasis en la etnicidad judía $^{3}$ - Jewish peoplehood. La identidad judía, principalmente en la diáspora ${ }^{4}$, siempre ha estado acompañada del vínculo étnico que de forma significativa conjuga a los ancestros, la historia y las prácticas culturales fungiendo como recurso que ha conservado la unidad del pueblo a lo largo de su dispersión.

Paradójicamente para los judíos, la otredad frente a lo externo le da una sensación de unidad, a pesar de la diversidad y complejidad interna del pueblo judío; el colectivo dispone de una cultura mínima común y está consciente de su sentido de formar parte de una "aldea judía global".

\footnotetext{
${ }^{3}$ La conciencia de pueblo se encuentra en evidente relación con la etnicidad refiriéndose a la combinación de parentesco y de costumbres, ambas reflejando genealogía compartida y comportamiento común. Webber, 1992.

${ }^{4}$ Las comunidades judías creadas en Latinoamérica a finales del siglo XIX y principios del XX fueron en base a sus orígenes étnicos geográficos.
} 
Las tradiciones son un identificador que surge como consecuencia de las transformaciones acontecidas en el seno del judaísmo a partir de la Modernidad donde aparece una nueva modalidad de reformulación e interpretación de la religión. A raíz de la secularización y otros factores, la autoridad de las prácticas religiosas fundadas indudablemente en la creencia en Dios entra en discusión, en duda y en disenso y las observancias de los preceptos (mitzvot) pasan a ser actos independientes a esta creencia. Dios no es siempre la autoridad en la ejecución de las prácticas distintivas judías; esto indica que la correspondencia mutua entre la observancia y las creencias, deja de ser axioma (Eisen, 1998). Consecuentemente, dentro de la experiencia religiosa del judío moderno, la prioridad de la práctica supera a la creencia. Parte del colectivo judío cesa de fundamentar y justificar sus prácticas en valores religiosos y los sustituye con valores laicos. Con esto, los preceptos, cuando se les suprime su significado e interpretación religiosa y de fe, resultan en tradiciones, su paralelo de corte secular. El judaísmo, en ciertas áreas, trasfiere su dominio religioso al campo cultural.

Al hablar del identificador Israel nos referimos a toda una filosofía y un simbolismo que han acompañado a este elemento a través de la historia del Pueblo Judío sumado al Estado de Israel, establecido en 1948. Durante los siglos de exilio y diáspora, el lazo con la Tierra de Israel se mantuvo presente en el sistema de valores del judaísmo y en su autoconciencia de colectivo como nación. Ha sido la ideología sionista la que ha enfatizado la visión del judaísmo como Pueblo (Am Israel); afirma su naturaleza étnica que, al proyectarle un contenido político, transforma al grupo étnico en una nación (en el sentido moderno de la palabra): "un grupo étnico con una bandera" (Gitelman, 1998).

En la actualidad, la existencia del Estado de Israel como referente de vida judía emerge como un identificador cuya centralidad ideológica, espiritual y vivencial interactúa con nuevas expresiones de la vida judía global.

La Shoa, opera como identificador que redefine la memoria colectiva, elemento fundamental para un pueblo que se nutre de su pasado para desarrollar presente y construir 
futuro. La memoria, ya sea individual o colectiva, significa la presencia activa del pasado en el presente en función de un futuro deseado o de un horizonte de expectativas proyectado (Bárcena, 2004). Para el pueblo judío la valoración de la memoria histórica es una piedra angular de su tradición cultural y religiosa. En un principio la memoria judía de la Shoa estuvo acompañada de un silencio generalizado que, con el transcurso de los años, denotó una apertura a testimoniar lo ocurrido. En los últimos años, las historias personales de los sobrevivientes de la Shoa y ellos mismos han adquirido un papel de suma relevancia en la memoria de la Shoa y del pueblo judío en su totalidad.

Cada uno de estos identificadores contiene múltiples variantes, interpretaciones y alcances que son dados a partir de la ubicación en que se coloca cada individuo y/o subgrupo judío, a la vez que ésta disposición condiciona el valor y el grado de relación e interacción que se guarda con los mismos.

\section{Identificadores ¿Cómo se trasmiten?}

Todos estos identificadores o particularidades del judaísmo, ¿cómo se trasmiten? ¿Cómo se logra la continuidad? Una de las herramientas esenciales para este objetivo es la educación. La escuela judía en la diáspora tiene como meta esencial el generar identidad judía entre sus discípulos. Lo que toda institución educativa judía pretende es marcar la diferencia, particularmente en lo referente al ámbito judaico, a través de enseñar y educar a sus alumnos el significado de la pertenencia al Pueblo Judío en la diáspora y en Israel, dándole validez a la enseñanza de una cultura particular dentro de la sociedad universal, globalizada y tendiente a la homogeneidad.

Por lo tanto, el objetivo es transformar los años que los alumnos transcurren en escuelas judías integrales en experiencias educativas y espirituales significativas, que fortalezcan su identidad judía y su compromiso personal con los valores judíos; aprecio de su herencia judía y su continuidad. 
La realidad contemporánea nos demuestra que la continuidad judía depende de la voluntad de cada individuo de seguir siendo judío; por tanto, es de suma importancia comprender que la función del educador judío es poder sembrar en los corazones de los jóvenes la semilla de la pertenencia judía como base de la prolongación como pueblo. A lo largo de los ciclos escolares la idea es poder transmitir al alumnado los rasgos esenciales que los hace diferentes y que es la razón (el quid) de porqué asisten al colegio judío y no a otra escuela.

La educación judía en Chile ha logrado muchos adherentes aunque no llega a ser el 50\% de la comunidad: el estudio del $\mathrm{CREJ}^{5}$ revela que el $42 \%$ de los niños y jóvenes menores de 18 años asisten a un establecimiento de educación judía, ya sea el Instituto Hebreo, el Maimónides School (de corte ortodoxo), el Colegio Hebreo de Viña del Mar, o los Ganim (jardines infantiles) en la etapa pre escolar.

\section{Creación del primer colegio hebreo en Chile $^{6}$}

A principios del siglo XX comienzan a llegar los primeros inmigrantes judíos a Chile. Estos individuos, con mucho esfuerzo buscan comunidad, por ende, se crean las instituciones necesarias que ayuden y posibiliten la transmisión y la continuidad del judaísmo en su nuevo hogar, Chile.

Siendo la educación un factor esencial para este objetivo, desde su arribo a Chile ya había una pequeña escuela o yeshiva donde los niños, después del ir al colegio nacional, acudían a este espacio para aprender hebreo y religión.

Finalmente, en 1930, se creó el Instituto Hebreo, colegio integral que complementaba de forma conjunta las materias locales con las judaicas.

\footnotetext{
${ }^{5}$ CREJ- Comité Representativo de las Entidades Judías de Chile.1995. Estudio Socio-Demográfico de la comunidad judía de Chile. Santiago, Chile

${ }^{6}$ Instituto Hebreo Dr. Chaim Weizmann 1930-2005, 75 años de vida.
} 
En lo que respecta a las materias judaicas, se enseñaba hebreo e idish (idioma característico del mundo ashkenazí de Europa oriental). Eran escasos los materiales que se tenían, así que se traía material de Buenos Aires o era de producción local, hechos por los mismos maestros que se encargaban de las materias judaicas.

El Instituto hebreo ofrece, desde sus orígenes, una educación para la diversidad, no selectiva, inclusiva y dirigida a un alumnado heterogéneo.

Al Instituto Hebreo, el ministerio de Educación le permite añadir el área de Humanidades, es así que para 1949, el colegio adopta el nombre de Dr. Chaim Weizmann. El colegio comenzó a incrementar su alumnado; para 1956 se inaugura la sede de Macul que funcionó hasta 1990. Ese mismo año, el Ministerio de Educación reconoce al hebreo como idioma oficial dentro del colegio.

Debido a que para la comunidad judía, esté donde esté, la educación es básica y necesaria, no permite que nadie se quede sin educación. Se funda el Fondo de Becas Ana Frank. Más adelante en 1992, ya en la nueva sede de Las Condes, se funda el FOBEJU, Fondo Probecas para la Educación Judía.

En 1976 pasa a ser parte de la Ort, por esto el colegio se denomina de ahora en adelante Instituto Hebreo Comprensivo Dr. Chaim Weizmann-ORT. En la década de 1990 el colegio se traslada a las nuevas instalaciones en Las Condes. En esta nueva infraestructura se contaba con espacios para los deportes, por lo que se dejó de ir al Estadio Israelita Maccabi (EIM) para tales fines. Se creó un casino kasher para que los alumnos pudieran almorzar en el colegio.

El pluralismo se encuentra dentro de los objetivos del Instituto Hebreo. El colegio debe de reflejar esta línea pluralista tomando en consideración la variada composición de sus alumnos, constituida por hijos de matrimonios mixtos, personas convertidas, laicos e incluso alumnos con cierto grado de religiosidad mayor que el promedio. 
Actualmente, en el Instituto Hebreo aprenden alrededor de 1300 alumnos y el establecimiento recibe a 700 familias.

\section{Enseñanza judaica ¿Cómo se aplica?}

Después de esta breve historia de la creación y evolución del Instituto Hebreo, se debe de entender cuál es la dinámica interna de la enseñanza del judaísmo y poder describir los cambios y adaptaciones que se han implementado con el propósito de continuar con su objetivo esencial de inculcar identidad judía a sus alumnos logrando en paralelo ser un colegio de excelencia académica.

Dentro de este colegio han existido tradicionalmente dos esquemas básicos de trabajo en el área judaica:

1) El esquema Académico. Se refiere a los programas curriculares que se imparten en la sala de clases por un docente especializado en la materia judaica.

2) El esquema de la Educación no formal. Se refiere a las actividades, que van más allá de la clase misma, donde se incluyen las fiestas, conmemoraciones y otros programas internos relacionados con el judaísmo, el Pueblo judío y el Estado de Israel.

Ambos esquemas, separados y combinados, son el conjunto que componen la transmisión de la identidad judía dentro del sistema escolar del Instituto Hebreo.

En el colegio son cuatro los puntos angulares enfatizados como referentes de la identidad judía, en los diferentes ciclos escolares: 
1. Entrega del libro de la Torá. En $3^{\circ}$ Básico se lleva a cabo el proyecto de la entrega a los alumnos su primer Sefer Tora (libro de la Biblia) por sus padres. Se realiza una ceremonia donde los mismos alumnos hacen una representación sobre algún tema bíblico.

2. Programa Shorashim (Raíces): Proyecto en el cual los alumnos de $8^{\circ}$ Básico realizan un álbum para conocer sus raíces judías a través de su propia historia familiar. Este álbum es parte de las materias de judaísmo. Al término se hace una ceremonia y actividad relacionada con el tema Shorashim con la participación de los alumnos, sus padres y abuelos. Desde el año 2008, el colegio participa en el concurso de SHORASHIM que organiza Beth Hatefutsoth (el museo de la Diáspora en Israel). Se seleccionan los mejores álbumes de los alumnos y se mandan a Israel para que compitan con otros álbumes similares de niños de otros colegios de la diáspora.

3. Viaje de estudios a Polonia e Israel. Excursión de los alumnos al término de $3^{\circ}$ Medio una semana a Polonia y tres semanas a Israel. Durante todo el año se prepara a los alumnos acerca de lo que fue la vida de los judíos en Europa en general y en Polonia en particular y sobre la Shoá y su impacto. Se prepara a los alumnos para su encuentro con Israel.

4. Graduación del Alma: Reunión que hacen todos los $4^{\circ}$ Medios al término del año escolar con el objetivo de comentar y conversar acerca de sus experiencias durante su pasaje por el IH.

Comencemos con los primeros grados: el jardín infantil. El trilingüismo se aplica desde que los niños entran al colegio, lo cual es posible desde el año y medio habiendo tres niveles anteriores a prekinder; lo que implica que el jardín se compone de cinco grados, antes de que los alumnos pasen a la Enseñanza Básica. El jardín, que en el instituto Hebreo se denomina Gan (jardín infantil, en hebreo) el aprendizaje es completo: inglés, hebreo y lengua materna. Por ello es que un lugar privilegiado ocupa la dinámica de las distintas lenguas que, con increíble naturalidad, manejan los niños en el gan. El proyecto de 
inmersión implica que cada clase tiene una teacher que se expresa en inglés a lo largo de todo el día, logrando la menor inferencia posible de la lengua materna, a la vez que tienen a una morá (maestra) que les inculca la parte judaica. Ciencias y matemática son en inglés, en los dos últimos años del gan. En esta última disciplina se trabaja con el exitoso Método Singapur, cuyo enfoque es el desarrollo del pensamiento lógico ${ }^{7}$.

El Departamento Judaico del Gan, es aquel que pone en marcha todo el aparato valórico y vivencial del judaísmo. La coordinadora de dicho Departamento indica que "A ninguno de nuestros talmidim (alumnos) se les ocurriría decir 'estudio hebreo', 'estudio Sucot', sino 'es Sucot', 'es Pésaj'. Hay una actitud vivencial, de plena apropiación del entorno, con naturalidad. Yo siempre digo que los niños en nuestro gan hablan un idioma llamado “yehudit" (judío), con el cual todos podemos identificarnos: me refiero a esas palabras que sólo decimos en hebreo y que son tan formadoras de identidad: "kitá" (clase), "talmidim" (alumnos), "Moshé” (Moises), “sucá” (cabaña). Decimos "paró”, "Yosef” y ”Mitzraim”, y no Faraón, José y Egipto. Decimos “Hagadá” e incluso “iparón shajor” (lápiz negro). Un idioma que un judío lo va a hablar en todo el mundo. El idioma es cultura" ${ }^{\text {. }}$

Así mismo, la sección judaica del gan tiene a su cargo el Proyecto Arajim (Valores): "Mes tras mes el gan entero se enfoca en expresar algún valor fundamental: solidaridad, comprensión, dar al necesitado o hasta algo tan esencial como el acto de saludar al prójimo. El Proyecto Arajim está basado en nuestro calendario judío. Me interesa que como judíos nuestros niños tengan el calendario lunar inserto en el cuerpo. ¿Viste la luna ayer? ¿Estaba llena? Seguro se nos va a acercar algún jag (festividad). Y cada jag se aprovecha para reforzar un valor esencial. Buscamos que el mundo judío tenga una traducción en el hacer diario". 9

Al pasar del Gan a la Básica, los alumnos ya van impregnados de un judaísmo que se les ha ido transmitiendo a lo largo de sus años preescolares de forma vivencial y concreta.

\footnotetext{
${ }^{7}$ http://cjch.cl/2013/11/el-gan-del-instituto-hebreo-semillero-de-la-comunidad/

${ }^{8}$ Idem.

${ }^{9}$ Idem
} 
El esquema Académico: Las materias de la enseñanza judaica en Básica y Media históricamente siguen siendo las mismas que desde la fundación del colegio, no obstante, bajo la demanda de los padres del alumnado escolar y el claro desafío del colegio de adaptarse al mundo moderno, el inglés pasó a tener un importante rol en la educación: se hace la incorporación de este idioma en todos los contenidos. A raíz de esto se incorpora el proyecto de trilingüismo: el inglés como herramienta para el mundo global, el hebreo como entrada a la cultura judía y el español... lengua nativa de todos.

A continuación se dará una breve descripción de las materias de orden judaico, ya con los cambios incorporados en los últimos años y que han sido parte integral del esquema académico del Instituto Hebreo.

\section{Materia: Hebreo}

El hebreo se enseña en tres modalidades diferentes:

I) De $1^{\circ}$ a $6^{\circ}$ Básico. Programa Talam.

A partir del 2008, se implementa el programa Talam ${ }^{10}$, con sede en Montreal, Canadá. Este nuevo recurso en la educación del hebreo, se debió a que, más allá de modernizar la enseñanza y transmisión del hebreo y del judaísmo, se debía subir el nivel de hebreo que iba en decadencia debido a la implementación del trilingüismo dentro de la curricula escolar. El hebreo como materia, perdió cargas horarias y esto provocó una disminución en su enseñanza y su aprendizaje. Con este programa se buscó el fortalecimiento de la lengua hebrea en paralelo con el aprendizaje de las festividades, de Estado de Israel y de temas actuales a través del hebreo.

"Talam consiste en enseñar a sus estudiantes el idioma hebreo bajo un programa

${ }^{10}$ http://www.talam.org 
especialmente diseñado para escuelas judeo-sionistas y de mayor prestigio de la diáspora cuyo objetivo principal es formar alumnos activos y participativos por medio de un proceso en aprendizaje gradual; estimular en los alumnos una identidad judía por medio del conocimiento y desarrollar el pensamiento cognitivo basándose en los diferentes tipos de inteligencias, todas herramientas que también pueden ser utilizadas en diversos ámbitos de la vida de los estudiantes. La estructura de Talam se basa en la idea que el mejor ambiente de aprendizaje para los niños es aquel en el que el conocimiento se adquiere a través de una variedad de actividades que utilicen cada uno de los cinco sentidos. Además de estudiar los libros de texto, los alumnos utilizan música, juegos y ayudas visuales para aprender el idioma hebreo y para desarrollar una profunda comprensión de los conceptos y los valores judíos. El Instituto Hebreo adaptó una serie de salas para poder potenciar el programa las que son aprovechadas por los diversos niveles."11

Las fortalezas que ha tenido la implementación de dicho programa son el mejoramiento en el nivel de hebreo de los alumnos, se redujeron los indicadores de indisciplina; mayor entusiasmo de las morot (profesoras) en lo pedagógico, lo judaico y en la cantidad de material disponible. El Programa es estructurado y planificado y existe una riqueza y gran cantidad de material de fácil manejo. Conlleva una visión estética y atractiva para los alumnos, es actual con un lenguaje que les habla a los alumnos. El material didáctico y profesional de nivel comparable e inclusive superior a los de inglés y programa oficial. Apunta al aprendizaje de las inteligencias múltiples ya que el mismo contenido lo aprenden desde varias perspectivas: visual, kinestésico y auditivo lo cual ayuda a la planificación diferenciada dentro de la clase misma sin discriminar a los menos avanzados.

Con el programa de Talam se proyectan los valores de la pertenencia, solidaridad y tradiciones, donde el hebreo se refleja como idioma unificador y único, como herencia y como cultura. A raíz de este plan se ha dado una Re-valorización del hebreo. Se ha logrado el objetivo referencial del colegio: la transmisión y consolidación de la cultura judía a través del lenguaje hebreo.

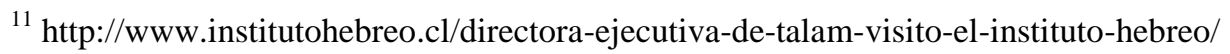


Las ventajas de la implementación de este programa en Chile es el ser parte de una red educativa de la diáspora.

II) De $7^{\circ}$ básico a $1^{\circ}$ Medio: Niveles.

Al terminar $6^{\circ}$ básico, al pasar al siguiente año hasta el primer año de la Media, las clases de hebreo no llevan la estructura de Talam, sino que ya son separados por niveles de hebreo dependiendo del logrado por cada alumno hasta ese grado escolar.

III) $2^{\circ}$ y $3^{\circ}$ Medio: Hebreo opcional. La enseñanza judaica pasa a ser impartida a través de diversos talleres opcionales. Entre las posibilidades está el continuar estudiando hebreo.

\section{Materia: Tora}

Los programas de Torá, desde el 2012, se dan dentro del plan de Talam. Comienzan en $3^{\circ}$ Básico con la ceremonia de la entrega de la Tora. A diferencia de años pasados, donde la materia se impartía en español, actualmente se imparte en hebreo. Esto ha sido relevante ya que el ser estudiada en el mismo lenguaje en que fue escrito, no se pierde su real significado en el momento de la traducción.

Los objetivos de la materia de Torá son enseñar historia, valores, consciencia de pueblo y nacionalismo judío, enseñar porqué Israel en Israel así como el paralelismo de las historias bíblicas con la actualidad: sistema Político, liderazgo, sociedad, jerarquías, colectivo vs. Individual, espiritual vs. Material. La idea del programa de Torá dentro de Talam es poder desarrollar las habilidades de comprensión de la Torá y sus comentarios, identificar las palabras guías claves, determinar el significado linguiístico de la repetición, descubrir y entender las elipses bíblicas y reconocer la narrativa bíblica. ${ }^{12}$

\footnotetext{
${ }^{12} \mathrm{http}: / /$ www.talam.org/talamD.html
} 
Torá comienza a darse en $3^{\circ}$ Básico hasta $6^{\circ}$ Básico. Al parecer este programa, siendo en hebreo y parte del programa Talam, ha tenido una gran recepción y aceptación entre los alumnos, lo cual ha llevado a que el próximo año escolar (2015) pueda ser implementado incluso a partir del segundo semestre de $2^{\circ}$ Básico.

\section{Materia: Historia}

Historia es una de las materias relevantes dentro del área judaica. Los objetivos de esta materia son enseñar historia judía dentro de un contexto universal, lograr el vínculo de la historia con la pertenencia al pueblo judío así como entender la línea de continuidad: pasado-presente-futuro. Se enseña historia judía desde sus comienzos, se pasa por la Edad Media, la modernidad y la actualidad. Se enseña la fundación del Estado de Israel, la vida antes de la Shoa y la Shoa misma. Esta materia se comienza a dar desde $7^{\circ}$ Básico hasta el fin de la Media.

\section{Materia: Talleres}

Los últimos dos años en la escolaridad ya no se dan específicamente clases de hebreo, Tora, o Historia. Lo que se ha implementado es que justamente cada una de estas áreas proponga talleres y los alumnos tengan una gama diversa de donde poder optar, así que cada semestre toman un taller diferente. Los talleres tienen que ver con la religión, los valores, actualidad en Medio Oriente, clases de hebreo, entre otras. Esta materia no siempre es dada por los profesores del colegio, sino que vienen gente externa como serían los rabinos o personalidades especialistas en la materia.

\section{El esquema de la Educación no formal}

Las cargas horarias no formales son en un promedio de 22 horas mensuales que se utilizan en este tipo de actividades fuera de clase, aunque generalmente se toman horas de las materias del área judaica. 
A continuación una lista de estas actividades:

- $\quad$ Fiestas y conmemoraciones del calendario hebreo generalmente se llevan a cabo fuera de la sala de clases, en actos o alguna actividad afín. Estas son: Purim, Pesaj (Pascua Judía), Iom HaShoá (Día de conmemoración del Holocausto), Iom Hazicaron (Día del recuerdo por los caídos en las guerras de Israel y el terrorismo), Iom Haatzmaut (Día de la Independencia de Israel) Lag Baomer, Yom Yerushalaim (Día de Jerusalem), Shabuot, Rosh Hashana (Año nuevo judío), Yom Kipur (Día del Perdón), Sucot, Simja Torá, La Noche de Cristales Rotos, Muerte de I. Rabin, y Januca (fiesta de las Luminarias).

\section{- $\quad$ Entrega del Sefer Tora}

\section{- Viaje de estudio}

- Semana Israel: Una semana durante el periodo escolar en que se toma un tema relacionado al Estado de Israel.De forma transversal se hace partícipe a todo el colegio.

- Actividades voluntarias (fuera del horario de clases): Coro (Makeila), Obra de teatro en español con tema judaico, Bailes (Leakot majol), entre otras.

Cabe destacar que no todos los cambios producidos al interior del colegio tienen relación con la enseñanza y la transmisión de judaísmo, muchos son adecuados a la excelencia académica y al desarrollo integral de sus alumnos.

1) Enseñanza para la diversidad: respeto a la heterogeneidad como rector de enseñanza en el aula de clases, desarrollando las distintas potencialidades de los alumnos.

2) Proyecto de Integración: dar acogida a niños con capacidades diferentes. 
3) Ampliación en la oferta de talleres en el área deportiva y el incentivo en la participación de la formación deportiva de los alumnos.

4) Hadarim: trabajo en conjunto entre maestros y padres cuyo fin es el diálogo entre ambos sectores, así como la relación entre los padres y sus hijos.

5) Impulso por la excelencia académica. Énfasis en las áreas relevantes para el futuro de los profesionales.

\section{Los cambios en la enseñanza judaica ¿Aires de globalización?}

La demanda por mayor calidad y cantidad en temas más universales por parte de los padres, ha provocado que el colegio judío preste mayor atención y priorice al idioma inglés y la tecnología afectando el estudio de las materias judaicas, disminuyendo la carga horaria asignada a estas mismas. No obstante que, con el énfasis en estas materias se ayuda a las nuevas generaciones a un mejor enfrentamiento con su futuro, ello viene en detrimento de la identidad judía, piedra angular del Instituto Hebreo. No se trata de ir contra esta corriente globalizadora, ya que todos somos parte del mundo en que vivimos, pero si se trata de buscar cómo adaptarse a estos nuevos y tan rápidos cambios (a veces incluso fugaces), manteniendo el énfasis en la identidad judía fundamental para la continuidad del pueblo judío. Por esto, el colegio se adapta a las exigencias de priorizar materias como el inglés y el área tecnológica.

Debido a estas nuevas exigencias por parte los padres, y de los cambios a nivel global, donde las horas de hebreo y materias judaicas disminuyeron y esto, sin duda, trajo una depreciación en la enseñanza del hebreo y judaísmo.

Con el objetivo de poder medir el impacto de esta contracción a nivel del judaísmo, hubo una petición del Instituto Hebreo para diseñar una prueba de conocimiento para ser aplicada 
a los alumnos que egresan de $3^{\circ}$ Medio. ${ }^{13}$ Esta prueba se diseñó basándose en el material de estudio de todas las materias judaicas impartidas en el colegio a lo largo de todo el ciclo escolar. Las cinco áreas en que estaba repartida la prueba fueron Torá, Israel, Historia Judía, Sionismo y Shoa, con un total de 70 preguntas. Se implementó a finales del año escolar 2012, y se aplicó a 71 alumnos de $3^{\circ}$ Medio.

El rendimiento de los alumnos, en términos generales, no fue el óptimo. Los datos analizados sobre este examen de conocimientos de judaísmo (denominado PSJ) arrojan un nivel relativamente bajo de sus alumnos. ${ }^{14}$

Con todos los cambios que se han descrito en el área de judaísmo, este panorama de bajo rendimiento escolar en lo relativo al conocimiento de las materias básicas de judaísmo se puede revertir, aunque no será de efecto inmediato, ya que se debe de esperar a que quienes están actualmente cursando la Básica (bajo el innovador programa de Talam), al llegar a la Media, ya el nivel sea mayor tanto en el conocimiento de la lengua hebrea como en lo que se refiere al judaísmo. Esto solo es posible medirse en algunos años por delante.

\section{Otras instancias de educación judía en Chile}

El Instituto Hebreo, desde su fundación ha sido considerado como una de las mejores instituciones educativas judías por sus características relevantes dentro del judaísmo latinoamericano: integral, secular, sionista, tradicionalista y hebreo. No obstante, décadas después, en 1998, surge un colegio de corte ortodoxo, el Maimónides School. La creación de este colegio refleja un cambio de mentalidad dentro de la misma comunidad judía en cuanto al aumento de la comunidad ortodoxa dentro de la comunidad judía de Chile. Es

\footnotetext{
${ }^{13}$ Esta prueba fue diseñada por Deby Roitman y Ana María Tapia-Adler, y se desarrolló a partir del material mismo del colegio.

14 La manera en la transmisión de la materia puede no ser la adecuada a la actual realidad de los alumnos, quienes en la actualidad viven empapados de tecnología y estímulos de todo tipo. Debido a esto es que podría existir la posibilidad de una mayor intervención de los alumnos en las clases, donde los profesores tienen la función de guiar y facilitar el óptimo aprendizaje de cada materia. La propuesta sería utilizar la metodología de talleres, donde se propicia una mayor interacción entre los alumnos; podría ser utilizando una metodología de rol-playing y no necesariamente optar por una clase frontal.
} 
relevante mencionar este punto para indicar que aunque el enfoque de la educación judía en Chile se ha puesto en el Instituto Hebreo Dr. Chaim Weizmann, existen el Maimónides School, y el Colegio Hebreo de Viña del Mar, los cuales salen del estudio de este artículo.

Otra instancia central en la comunidad judía en relación con la educación judía en Chile, son los movimientos juveniles, los cuales entregan un marco de educación no formal y de convivencia con otros niños y jóvenes judíos, concentrando a un altísimo porcentaje de la población judía en Chile. Al parecer se calcula que el 90 por ciento de los alumnos del colegio hebreo asisten los fines de semana a los grupos, donde todos estos movimientos son sionistas. ${ }^{15}$ Son cinco los movimientos presentes en Santiago más uno en Viña del Mar, en los cuáles participan el $63 \%$ de los niños y jóvenes judíos menores de 18 años. ${ }^{16}$

\section{Plantel docente del área Judaica}

Como ya se ha mencionado con anterioridad la educación judía del colegio judío como escuela integral, está basada en educación hebrea y sionista, que logre asegurar la continuidad del Pueblo judío.

Bajo este objetivo, son los educadores -particularmente los profesores de las materias judaicas, pero no solo ellos-, los encargados de impulsar y lograr inculcar a este público joven, durante su paso por los diferentes ciclos escolares, el aprendizaje y el fortalecimiento de la identidad judía.

El personal encargado de esta tarea debe de tener claridad de conceptos en cuanto a lo que es y significa la identidad judía. Lograr un fuerte sentido de pertenencia entre los alumnos no solo depende de la cantidad de conocimiento que se enseñe durante la etapa escolar sino que, en gran medida, del grado de motivación y de identificación con los diversos contenidos judaicos.

\footnotetext{
${ }^{15} \mathrm{http}: / /$ www.prensajudia.com/shop/detallenot.asp?notid=16459

${ }^{16}$ CREJ- Comité Representativo de las Entidades Judías de Chile. 1995
} 
El rol del more (profesor que imparte las materias judaicas) que forma parte del departamento judaico es la de transmitir identidad judía a través de la enseñanza de las materias de hebreo, torá e historia judía. Esto se refiere tanto al área académica así como la parte vivencial del judaísmo, que entra en el ámbito de la educación no formal y es tan importante como la académica.

La formación profesional y experiencia docente en las áreas judaicas es compleja. El problema con los docentes de estas materias es la dificultad de contar con profesionales calificados para estas materias, tanto en la educación judía formal y no formal. Las materias judaicas (como es el hebreo, historia judía y Biblia hebrea), no son temas que pueden ser aprendidos en cualquier universidad o institución educativa del país, y son pocos los lugares a los que se puede acudir en América Latina. Por ello no son muchos los que se han podido especializar en estas materias, constituyéndose en un recurso muy escaso en América Latina en general y en Chile en particular.

En términos generales se considera que el éxito de la educación depende directamente en la calidad de los docentes. Sin duda, la falta de un personal adecuadamente preparado y actualizado, tanto en los contenidos como en la pedagogía limita notablemente la calidad de la educación. Los estudios e investigaciones sostienen que la formación y la calidad del profesorado están estrechamente relacionadas con lo que aprenden los alumnos. ${ }^{17}$ Siguiendo en la misma línea se puede argumentar que, en términos generales, los colegios con bajos niveles de rendimiento escolar tienen bajo nivel de formación y profesionalización docente y viceversa.

Dentro del perfil judaico, existen tanto fortalezas como debilidades en el plantel de profesores. Como fortalezas se encuentra el compromiso afectivo, el conocimiento de la realidad de la sala de clase del colegio hebreo, el entusiasmo con programas innovadores y la disponibilidad a aprender y escuchar. Claro que, para que estas fortalezas lo sigan siendo,

${ }^{17}$ Fuente: Universidad Hebraica, documento interno, 2009. 
existe la necesidad de darles herramientas para manejo de clases así como la actualización docente: metodológica y de contenidos.

La constante capacitación de los profesores (sea la materia que sea) es de mayor relevancia, ya que la fórmula "mejor maestro, mejor alumno" debe primar con el fin de obtener resultados positivos y de largo plazo entre los alumnos del Instituto Hebreo.

\section{Ejes judaicos ¿Cuáles son?}

El colegio judío tiene como meta forjar jóvenes en un ambiente educativo formal judío. Para poder obtener logros, se debe comenzar por tener claridad en cuáles son los conceptos básicos a seguir. Se debe de plantear cuáles son los ejes judaicos generales dentro del marco escolar del colegio, cuya línea de acción se encuentra demarcada dentro de la ideología judeo-sionista. El aprendizaje de estos conceptos debería de ser la guía del proyecto escolar judío, más allá del mayor o menor compromiso familiar y colectivo que los alumnos pueden asumir en sus vidas privadas.

Los ejes judaicos que deberían ser incluidos dentro de todo programa escolar con el claro propósito de enseñar, inculcar y transmitir identidad judía a los alumnos a lo largo de todo el ciclo escolar: desde el jardín, Kinder hasta $4^{\circ}$ Medio, son justamente aquellos que se indicaron al principio del artículo como identificadores judíos.

- Pertenencia a un pueblo (Consciencia histórica): es el sentido de que son un pueblo unido al pasado y con una proyección hacia el futuro. El judío vive en la dimensión de la pertenencia y es un eslabón en un proceso colectivo que lo antecede y que lo continuará. La conciencia de pueblo se halla en clara relación con la etnicidad refiriéndose a la combinación de parentesco y de costumbres, ambas reflejando genealogía compartida y comportamiento común. 
- Tradición: Se manifiesta principalmente en un complejo de creencias, normas y valores particulares, así como en la constante realización de prácticas tradicionales.

- $\quad$ Solidaridad y valores éticos (Tikun Olam): Valores sociales del pueblo de Israel que tienen que ver con la justicia, la rectitud, la solidaridad, el sentido de responsabilidad ante el mundo y ante Dios. La expresión más elevada de la santidad de la vida está expresada en las relaciones humanas; y la justicia social como el máximo valor judío ya que este valor equilibra las relaciones humanas y la equidad en la satisfacción de sus necesidades.

- Estado de Israel: A partir de su creación, Israel ha sido fuente primordial de identidad, tanto para aquellos que lo habitan como para quienes viven en la diáspora. Israel se adviene como punto focal y medular en la identidad judía de la diáspora, aceptado virtualmente por el colectivo judío mundial, donde el rol crucial de Israel pasa a ser el de generar lazos judíos. Relevante la enseñanza de su historia y actualidad.

- Materialización y conocimiento del Judaísmo (Praxis y enseñanza judía): El judaísmo no sólo es una cuestión declarativa, se considera un estilo de vida. Se expresa en actos concretos, que reflejan los valores del judaísmo a través de la tradición y la historia. Esto se logra a través de:

1) Festividades y conmemoraciones: a través de la experiencia y vivencia de los festejos y conmemoraciones de los eventos relevantes del judaísmo se le inculca al alumnado la pertenencia al pueblo judío, así como el conocimiento de sus raíces.

2) Ciclo de vida: el judaísmo siempre ha mantenido rituales cíclicos, que se repiten cada año: estos marcan su ciclo de vida y su calendario anual, con algunos momentos sagrados que lo diferencian del resto Brit milá (Ceremonia de la circunsición), Bar mitzva (rito de pasaje para ser considerado adulto), Jupá (matrimonio judío) y Shivá (duelo judío). 
3) Vida comunitaria: espacios comunes dentro del ámbito judaico: instituciones judías, sinagogas, cementerios, etc.

\section{Impresiones finales}

Vivimos en un mundo globalizado, donde la tendencia a la homogenización y la uniformidad es cada vez mayor, donde la comunicación es inmediata y simultánea, y donde los cambios son tan veloces que a veces uno no se da cuenta de que algo existió cuando ya es historia.

Los judíos de la diáspora viven y son parte integral de este mundo sin fronteras, no obstante, es justamente por estas razones que se debe dar mayor relevancia a aquellas particularidades que hacen al judío ser parte de un pueblo, sin dejar de ser orgullosamente ciudadanos chilenos.

Para el grupo judío, que en Occidente siempre ha sido símbolo de Otredad -es el Otro minoritario e irreductible, el Otro por excelencia (Benbassa \& Attias, 2002; Serrano de Haro, 2004)- el fenómeno de la búsqueda y/o preservación de la identidad tan en boga en nuestros días no le es desconocido ni ajeno. Bajo este contexto de homologacióndiferenciación, la minoría judía en la diáspora siempre se ha caracterizado en la construcción y mantenimiento de su especificidad. La nueva apertura invita una vez más al individuo judío a ser parte de la sociedad que habita en calidad de ciudadano; pero al mismo tiempo, a raíz del despertar identitario universal, el colectivo judío presuntamente obtiene (al igual que otros colectivos minoritarios) legitimidad ante su transmisión y preservación grupal.

La idea es integrar, poder disfrutar de los dos mundos de los cuales son parte: el mundo judío y el mundo chileno. Poder integrar tanto los conocimientos universales que serán una excelente herramienta a futuro en lo que a éxito profesional y económico se refiere, sin 
dejar por ello de lado los conocimientos y vivencias del ámbito de lo judío, que permiten la continuidad como pueblo.

Hay que comprender y captar que no es únicamente la convivencia entre judíos como denominador común la que hace a uno pertenecer a un mismo pueblo sino el conocimiento y la práctica, por mínima que esta sea, del judaísmo.

Son los profesores de las materias judaicas, quienes deben de tener una preparación profesional tanto en las materias específicas que imparten así como en el modo y la forma en que el impacto de su materia obtiene los mejores resultados. Esto debe ser logrado a través de profesionalización y capacitaciones periódicas y sistemáticas. Sin una adecuada jerarquización y valorización del educador judaico, y de su aporte a la continuidad y creatividad del pueblo judío, se producirá un continuo desgaste de los sistemas educativos judíos, con el consiguiente deterioro y empobrecimiento de la calidad de vida judía. A nivel profesional, también debe de haber una coordinación, desarrollo y evaluación tanto de los docentes, como de sus programas de las materias judaicas.

En la actualidad, el modelo educativo y las fórmulas heredadas de las generaciones anteriores al parecer ya no responden a las expectativas de los padres, hay una mayor exigencia en el ámbito académico (aumentar el inglés, reducir el sionismo, el hebreo y las materias judaicas y lograr el liderazgo en pruebas y puntajes nacionales) y también en lo referente a la sociabilidad (no saturarse socialmente interactuando solo entre judíos). Ante esta situación, las escuelas judías no siempre han enfrentado adecuadamente las divergencias producidas por los cambios generacionales y los nuevos valores, expectativas comunitarias, pedagogías, formas de gestión educativa, así como el impacto de la nueva imagen de Israel.

Cabe preguntarse cómo se puede revertir esta situación y aquí entra el lema "Si no puedes contra ellos, úneteles", es decir, se debe justamente utilizar aquellos elementos que aparentemente son los que relegan a un segundo plano los estudios judaicos, como la 
tecnología y el estudio del idioma inglés. En la era de la globalización, el Instituto Hebreo debe adaptarse a las nuevas reglas del juego. Si las innovaciones tecnológicas son el leiv motiv de lo que sucede a nuestro alrededor, entonces se deben de aprovechar a nuestro favor; aceptar y adaptar los cambios e innovaciones que se presentan en el mundo y beneficiarse de ellos. Hacer de la tecnología y del inglés los aliados del colegio. Es decir, utilizar nuevas técnicas y formas innovadoras y atractivas de poder transmitir una cultura milenaria que no queremos se pierda sino más bien, asegure su continuidad. Buscar nuevas alternativas con el fin de hacer más interesantes y atractivas las materias a impartir.

Es así como en el Gan del Instituto Hebreo, se vive de forma concreta el trilingüismo lo cual esto ha provocado, en los últimos años, un aumento en la incorporación de nuevos alumnos. A través del proyecto Talam instalado en la Educación Básica la sensación de pérdida de valoración del área judaica dentro del Instituto Hebreo ha disminuido y se ha fortalecido las materias judaicas tanto en lo valórico como en lo académico.

En nuestros días, al parecer, el contexto emocional del judaísmo ya no puede ser provisto únicamente por la familia, por lo tanto debe ser suministrado por la escuela judía. Las expectativas actuales crean y provocan que sea el colegio judío aquel que provea la identidad judía, antes función tradicional delegada a la familia. Así es que el reto del colegio judío como un marco de formación de identidad -judía- es mucho más difícil que años anteriores, no solo porque la familia así lo exige y demanda, sino porque en el mundo de hoy hay una variedad enorme de distractores que dejan relegada la pertenencia al judaísmo como factor relevante en la vida tanto privada como colectiva del individuo judío. Aunque lo que nos atañe en este documento son las materias del área judaica, que es un departamento específico dentro del sistema escolar del Instituto Hebreo, se debe ver el colegio en su totalidad. Se debe tomar en consideración el comportamiento organizacional que tiene que ver con el hecho de que todo lo que ocurre en el colegio, aunque no pertenezca específicamente al área ya mencionada, tiene incidencia en ello y viceversa. 
A raíz de todo lo anterior se hace necesario que tanto alumnos, apoderados y profesores, estén motivados y que comprendan que el estudio de la temática judía es el instrumento clave para la transmisión y afianzamiento de la identidad judía que se pretende inculcar a los alumnos. Se debe tener claro que el simple hecho de estar en un colegio judío donde sus pares también lo son, si bien es condición necesaria, en ningún caso es condición suficiente como para que la identidad se mantenga y se asegure la continuidad judía.

El colegio hebreo ha sido el encargado de proveer a sus alumnos los elementos esenciales que conforman al judaísmo como fuente de identidad, y es justamente la articulación de dicha identidad la que se ha trasformado: se ha pluralizado. El Instituto Hebreo Dr. Chaim Weizmann tiene la difícil tarea de hacer procesar en la mente de sus alumnos, desde muy pequeños, las empanadas del 18 de septiembre y la manzana con miel, la sucá y las ramadas, todo como parte de su condición de judíos y chilenos a la vez. ${ }^{18}$

Teniendo a la "La Identidad Judía, la Excelencia Académica y la Formación Valórica"19 como los pilares fundamentales de una educación inclusiva, en un clima escolar amigable y de respeto esto puede lograrse. Difícil tarea, mas no imposible.

\section{Bibliografía}

Arnow, D. (1994). Toward a Psychology of Jewish Identity. A Multidimensional Approach. Journal of Jewish Communal Services. Volume 71:1, pp. 29-36.

Bárcena, F. (2004). Enseñar Auschwitz. El aprendizaje de una decepción. Revista Anthropos. No. 203, pp. 139-160.

\footnotetext{
${ }^{18} \mathrm{http}: / / c j c h . c \mathrm{l} / 2013 / 11 /$ el-gan-del-instituto-hebreo-semillero-de-la-comunidad/

${ }^{19}$ Proyecto Educativo Institucional (2012-2016) del Instituto Hebreo Dr. Chaim Weizmann, p. 6.
} 
Baron, S. W. (1965). La época moderna. Editorial Paidós: Buenos Aires, Argentina.

Benbassa, E. \& Attias, J.C. (2004). The Jew and the Other. Cornell University Press, Ithaca and London.

Birnbaum, P. \& Katzenelson (Eds.). (1995). Paths of Emancipation: Jewish, states and citizenship. Princeton University Press, Chapter One, pp. 3-36.

CREJ- Comité Representativo de las Entidades Judías de Chile. 1995. Estudio SocioDemográfico de la comunidad judía de Chile. Santiago, Chile.

Della Pergola, S. \& Lerner, S. (1995). La población judía de México; perfil demográfico, social y cultural. Universidad Hebrea de Jerusalén, El Colegio de México, Asociación Mexicana de Amigos de la Universidad Hebrea de Jerusalén, México D.F.

DellaPergola, S. (1999). Asimilación/Continuidad judía: tres enfoques. En J. Bokser Liwerant \& A. Gojman de Backal (Coord.) Encuentro y Alteridad (pp. 467-485). Editoriales: Universidad Nacional Autónoma de México, Universidad Hebrea de Jerusalén, Asociación Mexicana de Amigos de la Universidad de Tel Aviv y Fondo de Cultura Económica, México.

Eisen, A .(1998). Rethinking Modern Judaism. The University of Chicago Press, Chicago \& London.

Elazar, D. J. (1999). Reexaming the issue of Religion in the Public Square. Jewish Political Studies Review, I: 1-2.

Elazar, D.J.(1997/98). Jewish Comunal Structures Around the World. Journal of Jewish Communal Service. Volume 74:2/3, pp. 120-131. 
Estudio "La población docente de las escuelas judías de México: características, riesgos, oportunidades", Universidad Hebraica: Documento de estricta circulación interna. México, 2009.

Gitelman, Z. (1998). The decline of the Diaspora Jewish nation: Boundaries, Content, and Jewish Identity. Jewish Social Studies, 4:2, 112-132.

Goldstein, Y. (2005). La vida comunitaria judía en la Argentina y el Brasil hacia fines del Siglo XX y comienzos del Siglo XXI: una perspectiva sociológica. www.ort.edu.uy/sobieort/pdf.goldstein2.pdf

Herman, S. N. (1977). Jewish Identity: a social psychological perspective. Sage publications: Inglaterra.

Hobsbawm, E. (1998). La era de la revolución, 1789-1848. Grijalbo Mondador: Buenos Aires, Argentina.

Informe del Diagnóstico del Departamento Judaico. Documento interno, Julio, 2010. Instituto Hebreo Dr. Chaim Weizmann 1930-2005, 75 años de vida.

Katz, J. (1998). Out of the Guetto. Syracuse University Press, USA.

Los Adolescentes: ¿donde están? ¿Qué hacen? ¿Cuál es la imagen que tienen de las instituciones de la Comunidad? ¿Cómo viven y piensan su identidad judía? ¿Cómo acercarnos y acercarlos? Joint Distribution Committe, Argentina, 1997.

Proyecto Educativo Institucional (2012-2016) del Instituto Hebreo Dr. Chaim Weizmann.

Roitman, D. (2005). Identidad Colectiva y Consenso Cultural: El Grupo Judío en la Ciudad de México a Principios del Siglo XXI, un Estudio de Caso, Tesis Doctoral, Universidad Nacional Autónoma de México. 
Sacks, J. (1994). From Integration to Survival to Continuity: The Great Era of Modern Jewry. En J. Webber (ed.) Jewish Identities in the New Europe (pp.107-116). Littman Library of Jewish Civilization: London, England.

Serrano de Haro, A. (2004). La filosofía ante el Holocausto: orientaciones categoriales y bibliográficas. Revista Anthropos. No. 203, pp. 95-109.

Trahtemberg, Leon (2009). Ponencia para la Conferencia Internacional del LAJSA (Latin American Jewish Association) en la U. de Tel Aviv, 26 de julio del 2009 y para el coloquio de los Amigos de la Universidad de Tel Aviv Visión y Desafíos de las Comunidades Judías en América Latina, en la U. del Tel Aviv, 14 de julio del 2009).

Webber, J. (1992). Modern Jewish Identities: The Ethnographic Complexities. Journal of Jewish Studies, 43:2, pp. 246-267.

Webber, J. (1997). Jews and Judaism in contemporary Europe: religion or ethnic group?. Ethnic and Racial Studies. Volume 20:2, pp. 257-279.

http://cjch.cl/2013/11/el-gan-del-instituto-hebreo-semillero-de-la-comunidad/

http://www.institutohebreo.cl

http://www.prensajudia.com/shop/detallenot.asp?notid=16459 